\title{
Some Polysorbate Compounds as Corrosion Inhibitors for Carbon Steel in Hydrochloric Acid
}

\author{
M. Sobhi ${ }^{a, b}$ * M. Abdallaha, ${ }^{a, b}$ and E. Hfaez ${ }^{a}$
}

\author{
${ }^{a}$ Chemistry Department, Faculty of Science, Benha University, Benha, Egypt \\ ${ }^{b}$ Chemistry Department, Faculty of Science, Tabuk University, Tabuk, Saudi Arabia. \\ ${ }^{\circ}$ Chemistry Department, Faculty of Applied Science, Umm Al-Qura University, Makkah Al Mukaramha, Saudi \\ Arabia. \\ Corresponding author: mohamedsob7i@yahoo.com
}

\begin{abstract}
Some commercial non-ionic surfactants polysorbate, namely, polysorbate 80 , polysorbate 40 and polysorbate 20 , were tested as inhibitors for corrosion of $\mathrm{C}$-steel in $2.0 \mathrm{M} \mathrm{HCl}$ solution using weight loss, potentiodynamic polarization and electrochemical impedance spectroscopy techniques. It was found that all the three used compounds act as inhibitors for acid corrosion of C-steel. The inhibition efficiencies obtained by the three techniques were almost the same, and increase with increasing the hydrocarbon chain length and the surfactant concentration. The polarization studies show that these compounds act as mixed inhibitors. The inhibition action of these surfactants can be explained by their ability to adsorb on the metal surface making a barrier to mass and charge transfer. It was found that the adsorption of these surfactants follows Langmuir adsorption isotherm. The negative values of adsorption free energy indicating that the adsorption process is spontaneous and increases, for different surfactants, in the same direction as inhibition efficiency.
\end{abstract}

Keywords: C-steel; corrosion inhibition; polysorbate surfactants.

\section{Council for Innovative Research}

Peer Review Research Publishing System

Journal: Journal of Advances in Chemistry

Vol. 5 , No. 3

editor@cirworld.com

www.cirworld.com, member.cirworld.com 


\section{Introduction}

The use of inhibitors is one of the most practical methods for metals protection against corrosion in acidic media ${ }^{1}$. Acidic solutions are used extensively in chemical and several industrial processes such as acid pickling, acid cleaning, acid descaling and oil wet cleaning, etc. ${ }^{2}$. Chemical inhibitors are often used for these processes mainly to control the metal dissolution and acid consumption. Most of well-known acid corrosion inhibitors are organic compounds containing nitrogen, sulfur or oxygen atoms ${ }^{3-6}$. It has been found that most of the organic inhibitors act by adsorption on the metal surface ${ }^{7}$. This phenomenon is influenced by the nature and surface charge of metal, the type of aggressive electrolyte and the chemical structure of inhibitors ${ }^{8}$. Many studies were done on the corrosion and inhibition of carbon steel in acidic media ${ }^{9-13}$.The efficiency of the surfactants is higher than the other organic inhibitors because of surfactant compounds exist at the interface between corrosive media and steel surface by more concentration. Accordingly, the surfactant compounds are more efficient than the same organic compounds at the same concentration. The adsorbed species protect the metal from the aggressive medium, which causes decomposition of the metal. Adsorption depends not only on the nature and charge of the metal but also on the chemical structure of the inhibitor.The objective of this study is to investigate the effect of some polysorbate compounds on the corrosion of carbon steel in hydrochloric acid solution. The inhibition efficiency of these compounds was determined by using weight loss, potentiodynamic polarization, and electrochemical impedance spectroscopy (EIS) techniques.

\section{Experimental methods}

The carbon steel specimen used for this study has the following composition (wt. \%); $\mathrm{C}=0.26 ; \mathrm{Mn}=1.35, \mathrm{P}=$ $0.04, \mathrm{~S}=0.05, \mathrm{Nb}=0.005, \mathrm{~V}=0.02, \mathrm{Ti}=0.03$, and $\mathrm{Fe}$ to balance. For weight loss measurements, the test pieces were cut specimen in dimensions of $2 \times 2 \times 0.2 \mathrm{~cm}$. The coupons were successively abraded with $\mathrm{SiC}$ paper to a final finish using 1200 grade paper. Before immersion in the test solution $(50 \mathrm{ml})$, the dimensions of each coupon were ascertained. They were then degreased in AR grade acetone, etched in $\mathrm{HCl}$ for $30 \mathrm{~S}$, washed with double distilled water, followed by acetone, dried and weighed. Each of the C-steel specimens was immersed, for 24 hours, in $50 \mathrm{ml}$ of $2.0 \mathrm{M} \mathrm{HCl}$ solutions containing different concentrations of polysorbate compounds, at $25( \pm 1){ }^{\circ} \mathrm{C}$. The average weight loss for each to identical experiments was taken and expressed in $\mathrm{mg} \mathrm{cm}^{-2}$.

For potentiodynamic polarization technique, the carbon steel electrode was of dimensions of $1 \mathrm{~cm} \times 1 \mathrm{~cm}$ and was weld from one side to a copper wire used for electric connection. The sample embedded in glass tube of just larger diameter than the copper wire. Before each experiment, the exposed area was polished with different emery paper in the normal way starting from coarser to finer, followed by degreasing in acetone and finally washed with bi-distilled water, just before the insertion on the electrolytic cell. BDH grade hydrochloric acid was used for the preparation of the test solutions.

A three electrodes cell, with saturated calomel reference electrode (SCE) and platinum foil counter electrode was used in polarization experiments. Potentiodynamic polarization technique was carried out using a PS remot potentiostat with zum PS6 software for calculation of electrochemical parameters.

The impedance measurements were carried out at open circuit potential $\left(E_{\text {ocp }}\right)$ in the frequency range from 10 $\mathrm{kHz}$ to $100 \mathrm{mHz}$ with signal amplitude perturbation of $5 \mathrm{mV}$ by using a computer- controlled potentiostate (Auto Lab 30 , Metrohm). All experiments were performed using three-electrode system.

The used polysorbate surfactants are organic compounds which have surface active properties and commercially available with relatively low price. Three different polysorbate compounds are used in the present study, namely, polysorbate 20, 40 and 80 .Polysorbate compounds are basically polyoxyethelene sorbitan combined with different fatty acids. The number associated with the polysorbate name determines the predominant fatty acid contained in the polysorbate structure. Thus, for polysorbate 20,40 , and 80 , the acids are, respectively, monolaurate, monopalmitate and monooleate.

\section{Results and Discussion}

\subsection{Weight loss measurements}

The losses of weight of $\mathrm{C}$-steel sheets due to their immersion in solutions of $2.0 \mathrm{M} \mathrm{HCl}$ containing different concentrations of polysorbate compounds were measured. It was found that, the addition of any of the used three polysorbate compounds lowers the weight loss of the C-steel specimen than its value in the free acid solution. This result indicates that the three polysorbate compounds act as inhibitors for C-steel corrosion in hydrochloric acid solution. The inhibition efficiencies (IE \%) of different concentrations of the three polysorbate compounds are given in Table (1). The inhibition efficiency was calculated using the following equation:

$$
\mathrm{IE} \%=\frac{W_{o}-W}{w_{o}} \times 100
$$

where, $W_{0}$ and $W$ are weight loss of $C$-steel coupon in absence and presence of additives, respectively. 
Table1. Dependence of IE of polysorbate compounds on their concentrations as revealed from weight loss measurements.

\begin{tabular}{llll}
\hline \multirow{2}{*}{ Conc./ppm } & \multicolumn{2}{c}{ IE \% } & Polysorbate 80 \\
\cline { 2 - 3 } & Polysorbate 20 & Polysorbate 40 & 57.00 \\
200 & 52.00 & 56.00 & 63.10 \\
300 & 58.40 & 60.80 & 69.33 \\
400 & 62.11 & 67.80 & 74.00 \\
500 & 71.00 & 74.00 & 82.11 \\
\hline
\end{tabular}

Inspection of Table 1 reveals that, the inhibition efficiency increases as the inhibitor concentration is increased. This behavior could be attributed to the increase of the metal surface area covered by the adsorbed inhibitor molecules with the increasing inhibitor concentration. Furthermore, data in Table 1 show that the extent of inhibition of different polysorbate compounds depends on their structures. The inhibition efficiency increases in the following order:

Polysorbate $20<$ Polysorbate $40<$ Polysorbate 80

This sequence will be discussed later.

\subsection{Potentiodynamic polarization}

Figure. 1 represents the cathodic and anodic polarization curves of C-steel electrode, in $2.0 \mathrm{M} \mathrm{HCl}$ solutions containing different concentrations of polysorbate 40 compound as an example. Similar curves were also obtained for the polysorbate 20 and polysorbate 80 (not shown). Inspection of Fig. 1 reveals that, both anodic and cathodic polarization curves are shifted to less current density values in the presence of polysorbate compound. This behavior suggests the inhibitive action of the polysorbate compounds. The extent of the shift in current density increases with increasing of polysorbate compounds concentration. The values of corrosion current density (icorr), corrosion potential $\left(E_{\text {corr }}\right)$, anodic Tafel constant $\left(\beta_{\mathrm{a}}\right)$ and cathodic Tafel constant $\left(\beta_{\mathrm{c}}\right)$, excluded from polarization curves are given in Table 2. Inspection of Table 2 reveals that the corrosion potential of C-steel in the acid solution is largely shifted to less negative values (noble direction) upon addition of polysorbate compounds. The magnitude of this shift increases with increasing of the associated number of polysorbates and with increasing of the additive concentration.

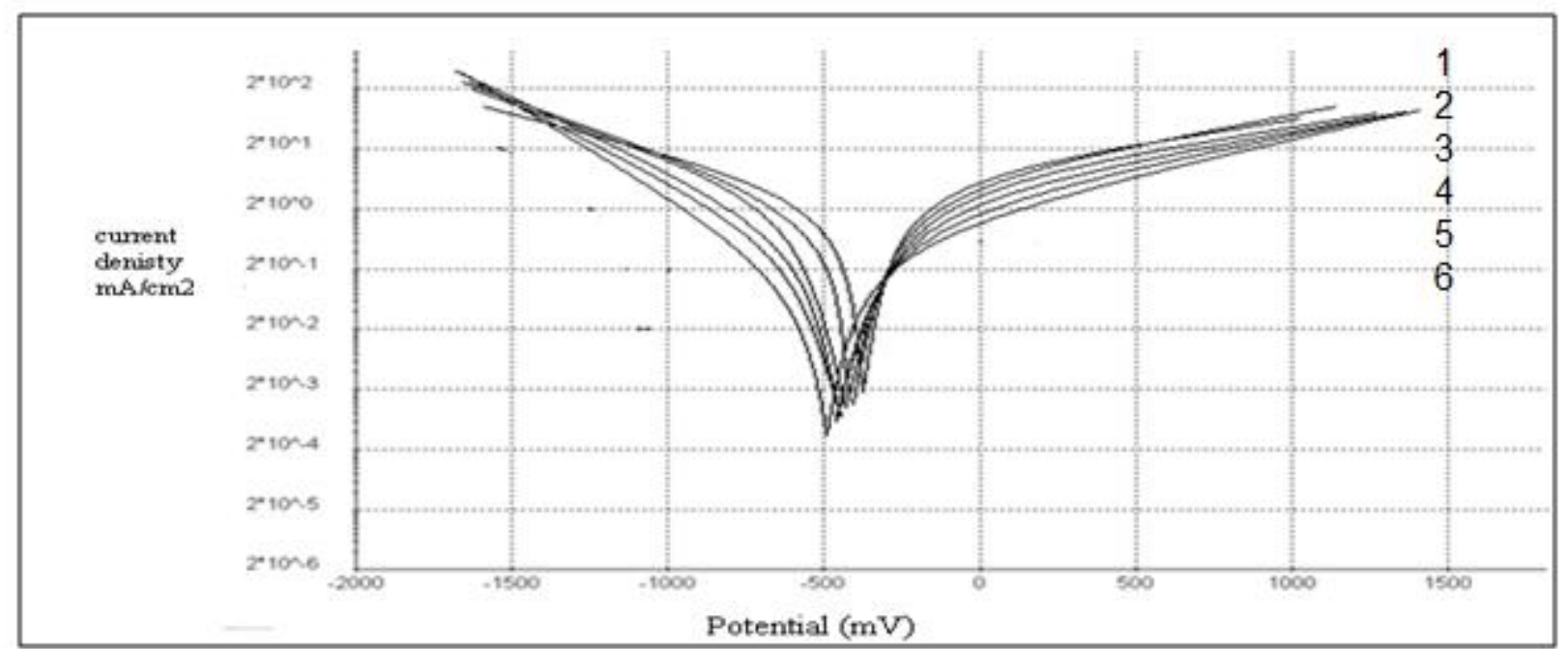

Fig.1. Potentiodynamic polarization curves of $\mathrm{C}$-steel electrode in $2.0 \mathrm{M} \mathrm{HCl}$ solution with and without polysorbate 40. (1) 0.00 ppm polysorbate 40, 2) 100 ppm, 3) 200 ppm, 4) 300 ppm, 5) 400 ppm, 6) 500ppm. 
On the other hand, the corrosion current density is greatly reduced upon addition of the three polysorbate compounds. These results suggest the inhibitive action of the tested compounds. The data in Table 2 reveal that the values of inhibition efficiency obtained by polarization technique are comparable to those obtained by weight loss measurements. The inhibition efficiency increases with increasing polysorbate concentration. The inhibition efficiency depends on the type of polysorbate compounds.

It could be recognized in Table 2 that the inhibition efficiency of the three polysorbate compounds increases in the following order:

\section{Polysorbate $20<$ Polysorbate $40<$ Polysorbate 80}

It is of interest to note that this sequence is similar to that obtained by weight loss measurements. Further inspection of Table 2 reveals that the addition of increasing concentrations of polysorbate compounds increases both the anodic and cathodic Tafel constants. This result indicates that the non-ionic surfactants act as mixed inhibitor which means that the surfactant molecules are adsorbed on both the anodic and cathodic sites resulting in an inhibition of both anodic dissolution and cathodic reduction reactions.

\subsection{Adsorption isotherm}

The inhibiting power of polysorbate compounds is mainly dependent on its ability to get adsorbed on the metal surface, The adsorption of inhibitor molecules from an aqueous solution can be regarded as a quasi-substitution process between the surfactant compound in the aqueous phase, $\mathrm{Surf}_{(\mathrm{aq})}$, and water molecules at the steel surface, $\mathrm{H}_{2} \mathrm{O}_{(\mathrm{sol})}$.

$\operatorname{Surf}_{(\mathrm{aq})}+\mathrm{x} \mathrm{H}_{2} \mathrm{O}_{(\mathrm{ads})}=$ Surf $_{(\mathrm{ads})}+\mathrm{x} \mathrm{H}_{2} \mathrm{O}_{(\mathrm{aq})}$

where, $x$ the size ratio, is the number of water molecules displayed by one molecule of organic inhibitor.

The degree of surface coverage $(\theta)$ which represents the fraction of the metal surface covered by adsorbed molecules is calculated using the following equation:

$$
\theta=\frac{i_{f}-i_{i n h}}{i_{f}}
$$

where, $i_{f}$ and $i_{n h}$. are the corrosion currents in free and inhibited acid solutions, respectively. The values of $\theta$ corresponding to different concentrations of polysorbate compounds are given in Table 2.

The values of surface coverage $\theta$ were found to increase with increasing the concentration of polysorbate compounds. This indicates that the inhibitive action of these compounds toward the acid corrosion of carbon steel could be attributed to the adsorption of its compound on the steel surface. Attempts were made to fit $\theta$ values to the several adsorption isotherms like Frumkin, Freundlich,Temkin and Langmuir. The best fit was obtained with Langmuir isotherm according to the following equation (Zhang and Hua, 2009):

$$
\log \frac{\theta}{1-\theta}=\log C+\log k
$$

where, $\mathrm{C}$ is the concentration of polysorbate compounds and $\mathrm{k}$ is the equilibrium constant of adsorption .

The standard free energy of adsorption, $\left(\Delta \mathrm{G}^{\circ}\right.$ ads $)$, was calculated from the equilibrium constant of adsorption using the following equation ${ }^{14}$ :

$$
k=\frac{1}{55.5} \exp \left[\frac{-\Delta \mathrm{G}_{a d S}^{o}}{R T}\right]
$$

where, $\mathrm{R}$ is the universal gas constant, $\mathrm{T}$ is the absolute temperature and 55.5 represents the concentration of water in mole $L^{-1}$

The plot of $\log \theta /(1-\theta)$ versus logarithm of polysorbate concentration give straight lines with slopes very close to unity for these compounds (Fig. 2). These results suggest that the adsorption of the polysorbate compounds on C-steel surface follows Langmuir adsorption isotherm. This isotherm postulates that there is no kind of interaction forces that could arise between the molecules adsorbed at the metal surface. Thus, the values of free energy of adsorption $\left(\Delta \mathrm{G}^{\circ}\right.$ ads $)$ are calculated using these equations. It was found that $\Delta G^{\circ}$ ads values are $-24,-23$ and $-21 \mathrm{~kJ}$ for polysorbate 20 , polysorbate 40 and polysorbate 80 respectively. The negative $\Delta G^{\circ}$ values suggest that the adsorption process is spontaneous. 
Table 2. Electrochemical parameters for C-steel corrosion in free and inhibited $2.0 \mathrm{M} \mathrm{HCl}$ solution.

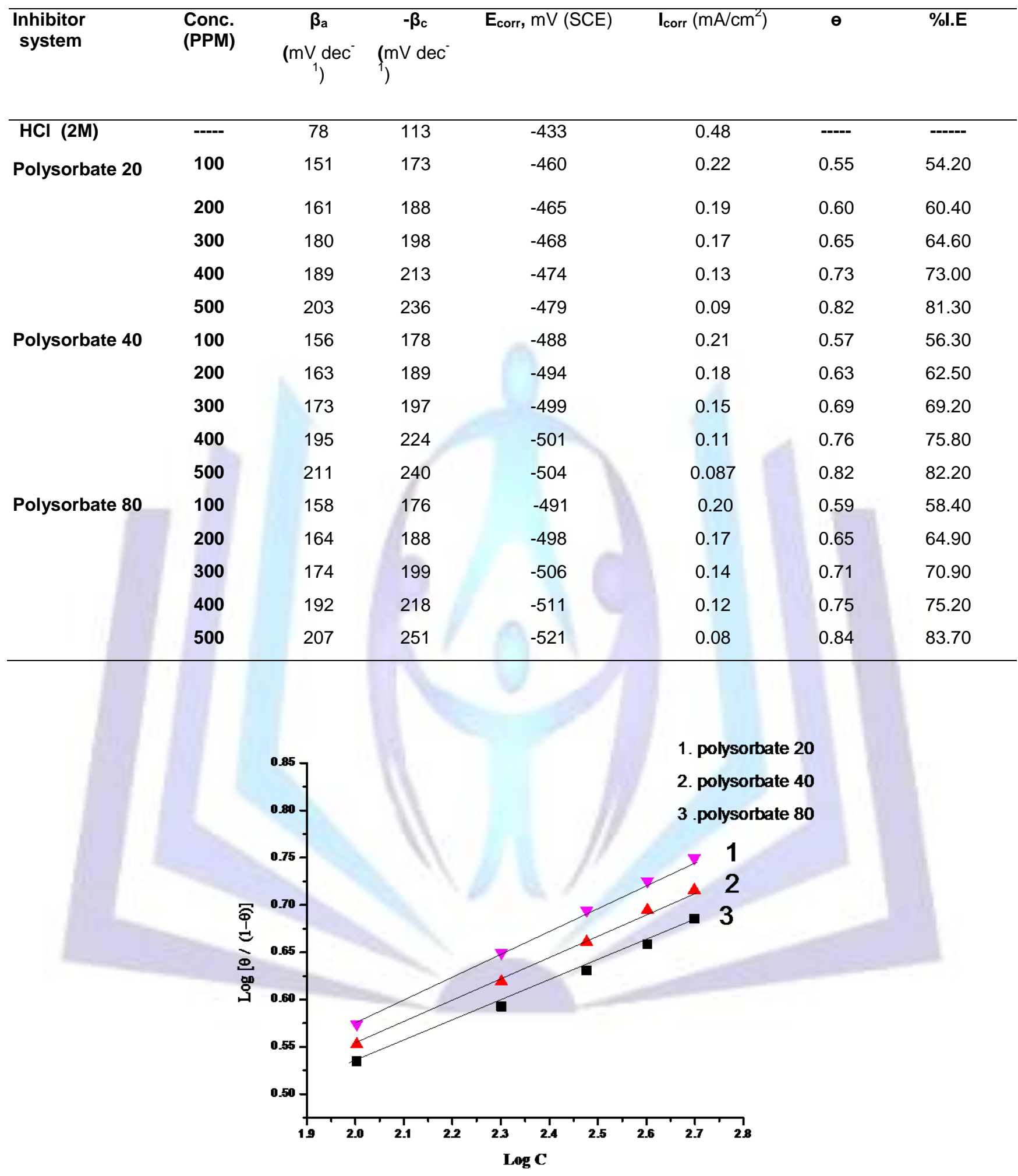

Fig. 2. Langmuir adsorption isotherms of different polysorbate compounds.

\subsection{Electrochemical impedance studies}

Electrochemical impedance measurements were carried over the frequency range from $10 \mathrm{kHz}$ to $100 \mathrm{mHz}$ at open circuit potential. The sample equivalent Randle circuit for studies is shown in Fig. 3, where Rs $\left(\Omega \mathrm{cm}^{2}\right)$ represents the 
solution and corrosion products film; the parallel combination of resistor, $R_{c t}$ (charge transfer resistance) and capacitor $C_{d l}$ (double layer capacitance) which represents the corroding interface.

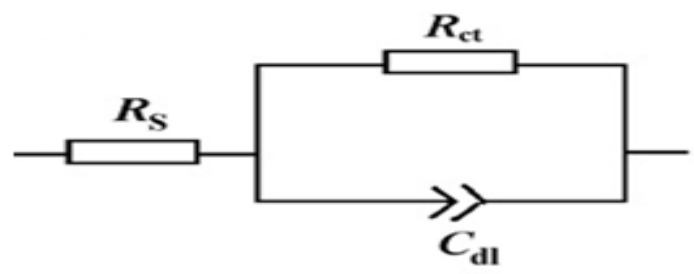

Fig.3. Electrical equivalent circuit $\left(R_{s} \Omega=\right.$ uncompensated solution resistance, $\mathbf{R}_{c t}=$ charge transfer resistance and $\mathrm{C}_{\mathrm{dl}}=$ double layer capacitance).

The Nyquist representation of the impedance behavior of carbon steel in $2.0 \mathrm{M} \mathrm{HCl}$ with and without addition of various concentrations of inhibitor is given in Fig.4. It is seen that addition of inhibitor increases the value of $R_{c t}$ and reduces $\mathrm{C}_{\mathrm{dl}}$.

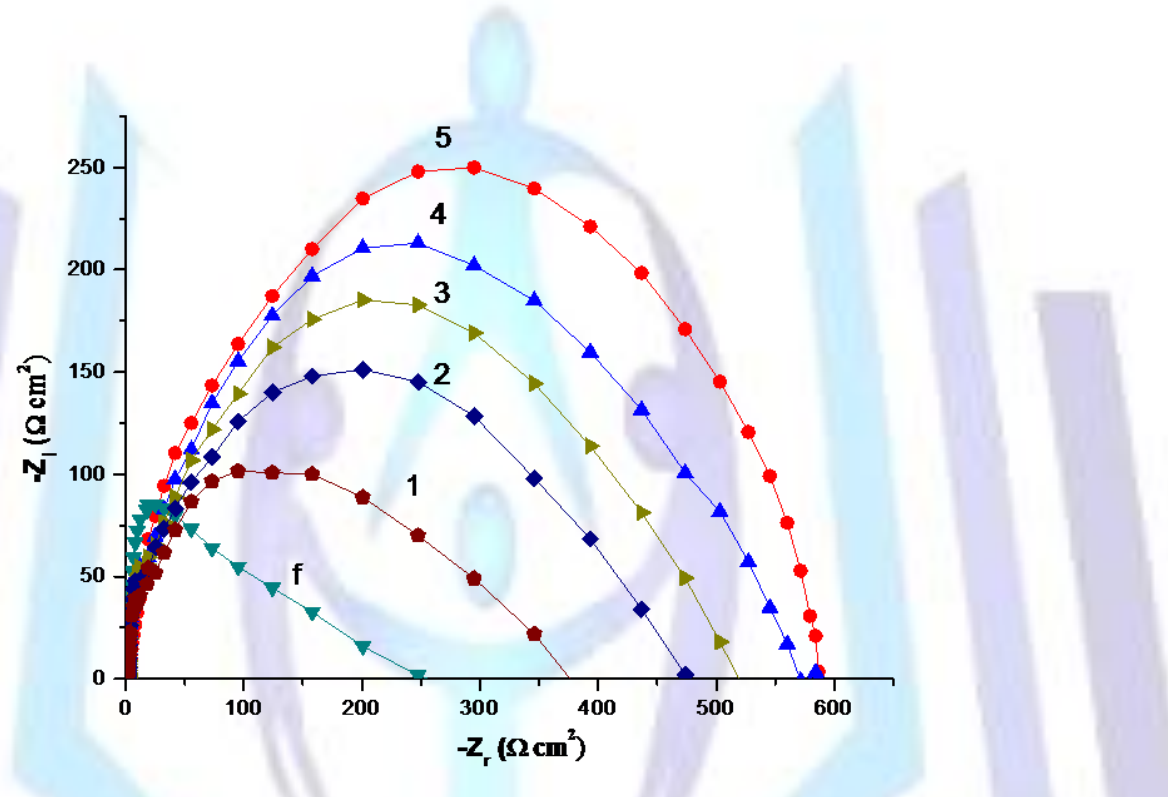

Fig.4. Nyquist plot of $\mathrm{C}$-steel in $2.0 \mathrm{M} \mathrm{HCl}$ solution in absence and presence of different concentrations of polysorbate 80: (1) 0.00 ppm (2) 100 ppm (2) 200 ppm (3) 300 ppm (4) 400 ppm (5) 500 ppm.

The $R_{c t}$ values of the investigated compound increase with increasing inhibitor concentration. At the same time the $\mathrm{C}_{\mathrm{dl}}$ has opposite trend in the whole concentration range. These observations clearly bring out the fact that the corrosion of carbon steel in $2.0 \mathrm{M} \mathrm{HCl}$ is controlled by a charge transfer process. The decrease in $\mathrm{C}_{\mathrm{dl}}$ is due to the gradual replacement of water molecules by the adsorption of the organic molecules at metal / solution interface, leading to a protective film on the steel surface, and then decreasing the extent of dissolution reaction ${ }^{15}$. The characteristic parameters associated to the impedance diagrams $\left(R_{\mathrm{ct}}, \mathrm{C}_{\mathrm{dl}}\right), \theta$ and IE $(\%)$ are given in Table 6 . The IE (\%) and $\theta$ were calculated from the following equations.

$$
\begin{gathered}
\theta=\left[\frac{\left(1 / R_{c t}\right)_{0}-\left(1 / R_{c t}\right)}{\left(1 / R_{c t}\right)_{0}}\right] \\
\% \text { I.E }=\left[\frac{\left(1 / R_{c t}\right)_{0}-\left(1 / R_{c t}\right)}{\left(1 / R_{c t}\right)_{0}}\right] \times 100
\end{gathered}
$$

where $\left(R_{c t}\right)_{0}$ and $\left(R_{c t}\right)$ are the uninhibited and inhibited charge transfer resistance, respectively ${ }^{16}$. 
Table 3: Impedance data and surface coverage for carbon steel in $2 \mathrm{M} \mathrm{HCl}$ in absence and presence of different concentrations of polysorbate compounds.

\begin{tabular}{|c|c|c|c|c|c|c|}
\hline Inhibitor & (M) & $\mathbf{R}_{\mathrm{s}}\left(\Omega \mathrm{cm}^{2}\right)$ & $\mathbf{R}_{\mathrm{ct}}\left(\Omega \mathrm{cm}^{2}\right)$ & $\mathrm{C}_{\mathrm{dl}}\left(\mu \mathrm{f} . \mathrm{cm}^{2}\right)$ & $\boldsymbol{\theta}$ & IE (\%) \\
\hline & 0 & 1.2 & 65 & ----- & $\begin{array}{l}---- \\
\end{array}$ & $\begin{array}{l}---- \\
\end{array}$ \\
\hline & 0.01 & 1.1 & 448 & 41.2 & 0.8549 & 85.49 \\
\hline & 0.02 & 1.8 & 500 & 36.13 & 0.8700 & 87.00 \\
\hline \multirow[t]{5}{*}{ Polysorbate 20} & 0.03 & 2.1 & 551 & 34.14 & 0.8820 & 88.20 \\
\hline & 0.04 & 2.3 & 570 & 28.26 & 0.8860 & 88.60 \\
\hline & 0.05 & 2.7 & 585 & 20.4 & 0.8889 & 88.89 \\
\hline & 0.001 & 1.2 & 420 & 40.88 & 0.8452 & 84.52 \\
\hline & 0.002 & 1.7 & 433 & 37.18 & 0.8499 & 84.99 \\
\hline \multirow[t]{5}{*}{ Polysorbate 40} & 0.003 & 1.9 & 538 & 33.2 & 0.8792 & 87.92 \\
\hline & 0.004 & 2.2 & 565 & 26.15 & 0.8850 & 88.50 \\
\hline & 0.005 & 2.6 & 580 & 21.4 & 0.8879 & 88.79 \\
\hline & 0.01 & 1.1 & 385 & 40.33 & 0.8312 & 83.12 \\
\hline & 0.02 & 1.3 & 470 & 36.45 & 0.8617 & 86.17 \\
\hline \multirow[t]{3}{*}{ Polysorbate 80} & 0.03 & 1.6 & 520 & 32.14 & 0.8750 & 87.50 \\
\hline & 0.04 & 1.9 & 560 & 26.28 & 0.8839 & 88.39 \\
\hline & 0.05 & 2.3 & 585 & 14.25 & 0.8889 & 88.89 \\
\hline
\end{tabular}

\subsection{Mechanism of inhibition}

The inhibition mechanism of the corrosion of carbon steel in hydrochloric acid by some polysorbate compounds (non-ionic surfactants) was studied. The percentage inhibition efficiency was calculated by chemical techniques e.g. weight loss measurement, and electrochemical techniques e.g. potentiodynamic polarization, electrochemical impedance spectroscopy and potentiodynamic anodic polarization technique at scan rate of $1 \mathrm{mV} / \mathrm{sec}$, to measure the pitting corrosion. It was found that the percent of inhibition efficiency of polysorbate compounds is dependent on its concentration.

These observations indicate that the corrosion inhibition is due to the adsorption of the inhibitors at the metal / solution interface. The nature of interaction of inhibitor on the metal surface during corrosion inhibition can be explained in terms of its adsorption characteristics.

However, the inhibition efficiency depends on many factors, which include the number of adsorption active centers in the molecule and their charge density, molecular size, mod of adsorption, temperature, heart of hydrogenation and formation of metallic complexes. The adsorption of these compounds on the metal surface cans retard the anodic or cathodic reaction by one or more of the following mechanisms.

i) Formation of physical barrier layer between metal and inhibitor.

ii) Reducing the metal reaction through alternating the nature of metal surface.

iii) Changing the structure of the metal /solution interface.

The inhibiting effect of some polysorbate compounds is due to its adsorption on the steel surface. The adsorbed layer acts as a barrier between the metal surface and the aggressive solution leading to a decrease in corrosion rate. The surface activity of polysorbate compounds as well as the presence of function groups, such as carbonyl group, in their structures facilitates such adsorption. The surfactant molecules adsorb on the metal surface via their function groups, while their hydrocarbon chains are oriented toward the aqueous solution. Since these hydrocarbon chains are hydrophobic in nature, they repel the aqueous aggressive anions away from the metal surface and therefore inhibit the corrosion 
reaction. The obtained results by different techniques indicate that the order of inhibition efficiency of the polysorbate compounds depending on the chemical structure of these compounds and decreases in the following order

\section{Polysorbate $20<$ Polysorbate T40 < Polysorbate T80}

This sequence reflects the effect of type of the fatty acid included in the chemical structure of polysorbate on their inhibitive action.

Now, one can rewrite the above sequence according to the alkyl chain as following:

$$
\text { Oleate }(\mathrm{C} 18)>\text { Palmitate }(\mathrm{C} 16)>\text { Luarate }(\mathrm{C} 12)
$$

This new sequence illustrates the effects of both hydrocarbon chain length and the presence of double bond in the inhibitor structure. The values of the percentage inhibition efficiency of some polysorbate compounds toward the corrosion of carbon steel in hydrochloric acid using different techniques show an agreement and conformity of the experimental results. However, there is a small difference in the values obtained. This observed discrepancy could be attributed to the difference of the experimental conditions

\section{Conclusions}

1- The tested polysorbate compounds inhibit the corrosion of $\mathrm{C}$-steel in $2.0 \mathrm{M} \mathrm{HCl}$ solution.

2- Polysorbate compounds inhibit the C-steel corrosion by adsorption on its surface and act better than the passive oxide film.

3- The inhibition efficiency increases as the length of the polysorbate hydrocarbon chain is increased.

4- The inhibition efficiencies of the tested polysorbate compounds increase with increasing of their concentrations.

\section{References}

1. Trabanelli, G., 1991. Inhibitor-an old remedy for a new challenge. Corrosion 47, 410- 419.

2. Lagrenée, M., Mernari, B., Bouanis, M., Traisnel, M., Bentiss, F., 2002. 2, 5-bis (n-methoxyphenyl)-1, 3, 4oxadiazoles used as corrosion inhibitors in acidic media: correlation between inhibition efficiency and chemical structure. Corros. Sci. 44, 573-588.

3. Abdallah, M., Meghed, H.E., Sobhi, M. 2009. Inhibiting effect of $\mathrm{Ni}^{2+}$ cation, 3-methyl pyrazolone and mixtures of them as corrosion inhibitors for carbon steel in sulfuric acid solutions. Mater. Chem. Phys. 118, 111-117.

4. Abdallah, M., Zaafarany, I. Khairou, K.S., Sobhi, M., 2012. Inhibition of Carbon Steel Corrosion by Iron (III) and Imidazole in Sulfuric Acid. Int. J. Electrochem Soc., 7(2), 1564-1579.

5. Abdallah., M., Basim, H., Zaafarany, I., Fouda, A.S. 2012. The Inhibition of Carbon Steel Corrosion in Hydrochloric Acid Solution using Some Phenolic Compounds. Int. J. Electrochem Sci.7 (1), 282-304

6. Abboud, Y., Abourriche, A., Saffaj, T., Berrada, M., Charrouf, M., Bennamara, A., Hannache, H. 2009. A novel azo dye, 8-quinolinol-5-azoantipyrine as corrosion inhibitor for mild steel in acidic media. Desalination 237, 175 189.

7. Hegazy, M.A., Abdallah, M., Ahmed, H. 2010. Novel cationic gemini surfactants as corrosion inhibitors for carbon steel pipelines. Corros. Sci., 52, 2897-2904.

8. Abd EL-Rehim, S.S., Ibrahim, A.M., Khaled, K.F., 1999. 4-aminoantipyrine as an inhibitor for mild steel corrosion in $\mathrm{HCl}$ solution. J. Appl. Electrochem. 29, 593-599.

9. De Souza, F.S., Spinelli, A. 2009. Caffeic acid as a green corrosion inhibitor for mild steel. Corros. Sci. 51, 642649.

10. Ghareba, S., Omanovic, S., 2010. Interaction of 12-aminododecanoic acid with a carbon steel surface: Towards the development of green corrosion inhibitors. Corros. Sci. 52, 2104.

11. Zucchi, F., Trabanelli, G., Brunoro, G., 1992. Iron corrosion inhibition in hot $4 \mathrm{M} \mathrm{HCl}$ solution by tcinnamaldehyde and its structure related compounds. Corros. Sci., 33, 1135-1139.

12. Moretti, G., Quartarone, G., Tassan, A., Zlngales, A., 1996. 5-Amino and 5-Chloro-indole as mild steel corrosion inhibitor in $1 \mathrm{~N}$ sulphuric acid. Electrochim. Acta 41, 1971-1980.

13. Moussa, M.N.H, El-Far, A.A., El-Shafei, A.A., 2007. The use of water soluble hydrazones as inhibitors for the corrosion of carbon steel in acidic medium. Mater. Chem. Phys. 105, 105-113.

14. Quraishi, M. A., Sudhish Kumar Shukla, 2009. Poly (aniline-formaledehyde): A new and effective corrosion inhibitor for mild steel in hydrochloric acid. Mater. Chem. Phys. 113, 685-689.

15. Shengtao Zhang, Zhihua Tao, Weihua Li, Baorong Hou, 2009. The effect of some triazole derivatives as inhibitors for the corrosion of mild steel in 1M hydrochloric acid. App. Sur. Sci. 255, 6757-6763. 
16. Shuduan Deng, Xianghong Li, Hui Fu. 2011. Acid violet $6 \mathrm{~B}$ as a novel corrosion inhibitor for cold rolled steel in hydrochloric acid solution. Corros. Sci. 53, 760-768.

17. Behpour, M., Ghoreishi, S. M., Soltani, N., Salavati-Niasari, M., 2009. The inhibitive effect of some bis-N, Sbidentate Schiff bases on corrosion behavior of 304 stainless steel in hydrochloric acid solution. Corros. Sci. 51, 1073-1082. 